\title{
Evaluating the quality of Covid-19 related information on the website of the Iran Ministry of Health and Medical Education
}

\author{
Fatemehzahra Ahmadi $^{1 *}$, Susan Taghizadeh ${ }^{2}$, Somayeh Esmaeeli ${ }^{3}$ \\ 1. Organization for Educational Research and Planning, Tehran, Iran \\ 2. Iran University of Medical Sciences, Tehran, Iran \\ 3. Al-Zahra University, Tehran, Iran
}

Received: 27 September 2021

Accepted for publication: 6 March 2021

[EPub a head of print-3 April 2021]

Payesh: 2021; 20 (2): 213-221

\begin{abstract}
Objective (s): Limited health literacy is a common problem in many countries worldwide. In Iran, about half of Iranian has limited health literacy. They have problems in understanding health information and making healthy decisions in critical situations such as Covid-19 pandemic. Thus it is necessary to make health information understandable to intended audiences. This quantitative study aimed to evaluate the quality of Covid-19 related information appeared on the website of Iran Ministry of Health and Medical Education.

Methods: We searched the term covid-19 on the website of Iran Ministry of Health and Medical Education. Once inter-coder reliability was established between two researchers, we evaluated the quality of each COvid-19 related information using the Clear Communication Index (CCI).

Results: The mean CCI score for the evaluated information was $38.87(\mathrm{SD}=9.72)$ none achieved a score higher than 90 . The findings showed that the quality of included information were not desirable according to the criteria for designing instructional material for people with limited health literacy. In the subsections, the main message, the call to action for action and language were lower than expected. Adherence to information design, tips and behavioral recommendations was significantly higher than expected.

Conclusion: To move toward a health literate public that is capable of combating epidemics such as Covid-19 pandemic there is a need to enhance the quality of information by using evaluation tools such as CCI.
\end{abstract}

Key Words: Evaluation, Covid- 19, Instructional Media

\footnotetext{
* Corresponding author: Organization for Educational Research and Planning, Tehran, Iran

E-mail: Midwife79@gmail.com
} 


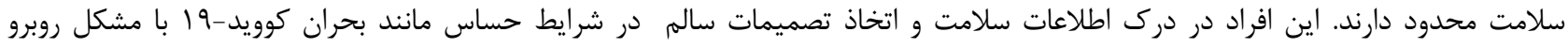

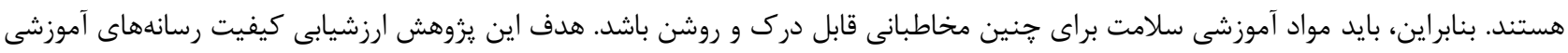

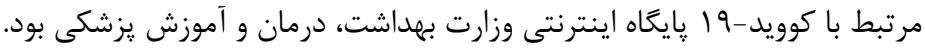

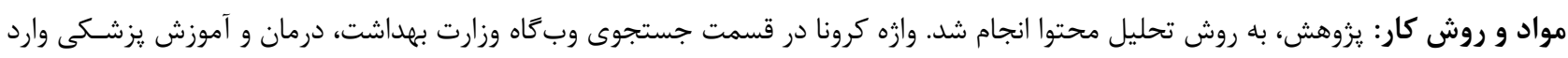

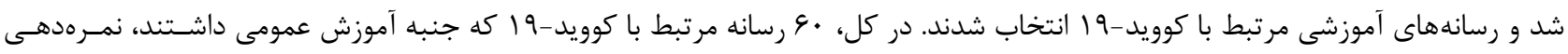

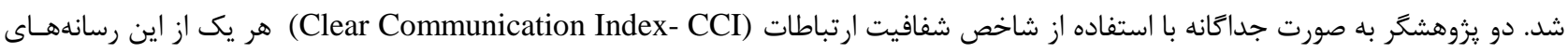

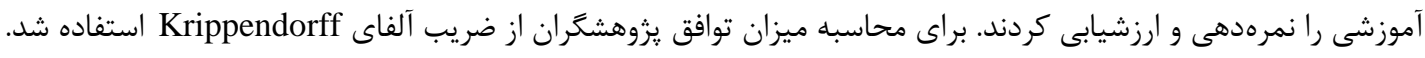

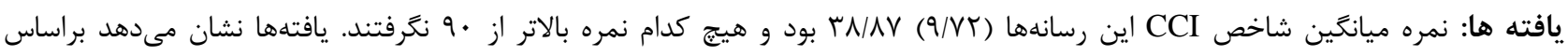

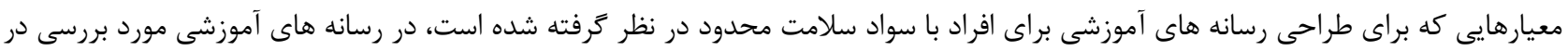

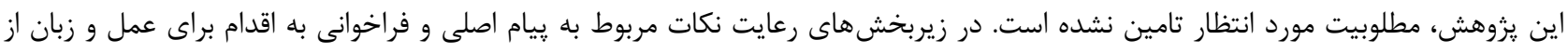

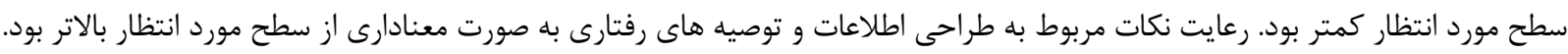

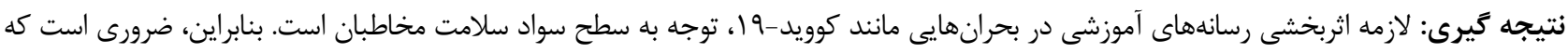

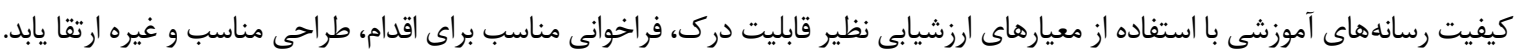


وجود، در بسيارى از كشـورها سـطح سـواد سـلامت هـايين اسـت و و

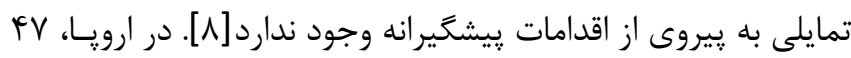

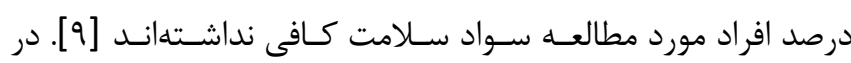
ايران، نتايج يك يزوهش ملى نشان داد كه نيمى از مردم ايران سواد

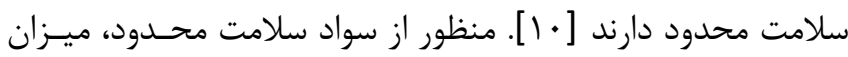

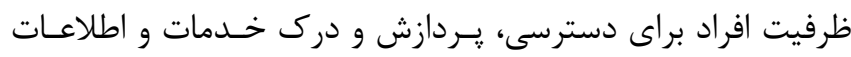

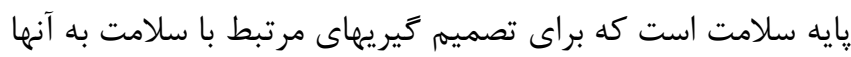

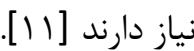
براى به حداقل رساندن آسيب به اين افراد و خدمت رساني لإنى به آنـان،

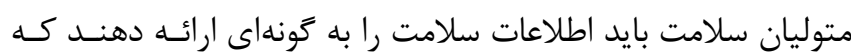

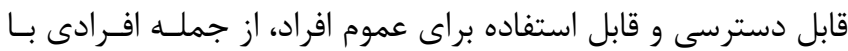

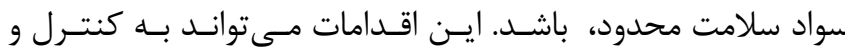

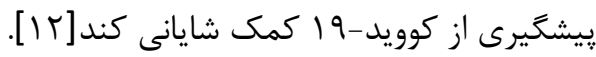

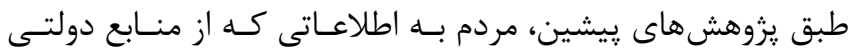

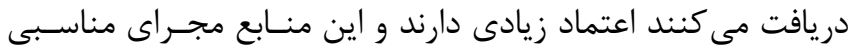

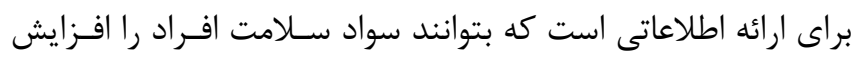

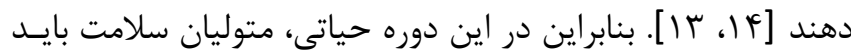

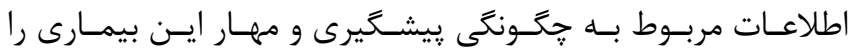

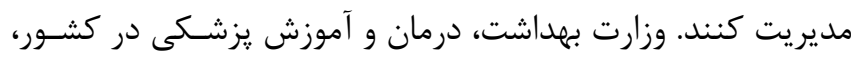

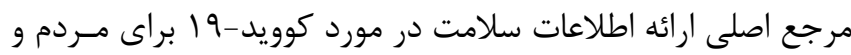

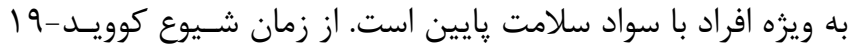

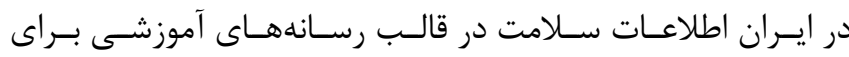

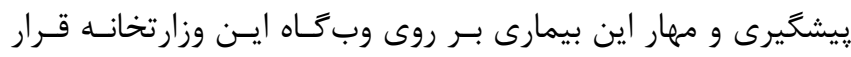
كرفته است. اما كيفيت اين رسانهها و تناسب آن براى افر آداد با سـواد سلامت پايين، اهميت به سزايى دارد. به اين ترتيب، اين مطالعه در

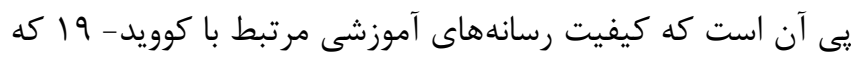

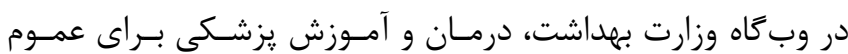
مردم تهيه و منتشر مىشود را ارزشيابى كند.

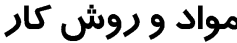

اين يزوهش، از حيث نوع دادهها از جمله يزوهششهاى كمى، از بعـد هدف در زمره يزوهشهاى كاربردى و از نظر روش كردآورى دادهـــا

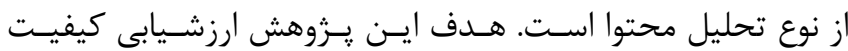

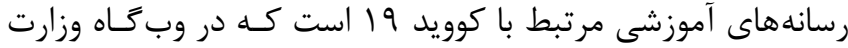

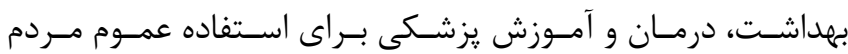

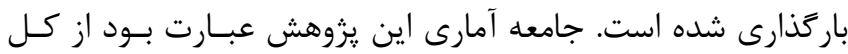

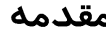

همه كيرى جهانى كوويد-19 فضاى مجازى را به يكى از منابع اصلى

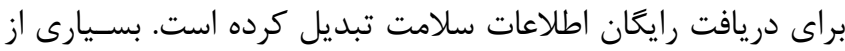

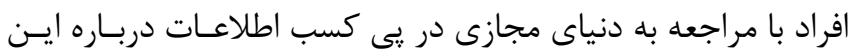
بيمارى نوظهور و كاوش در مورد وضعيت سلامتى خود بر مى آينـد. اينترنت منبعى جذاب و غنى براى كسب اطلاعـات فـورى در مـورد

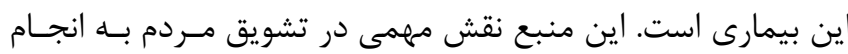

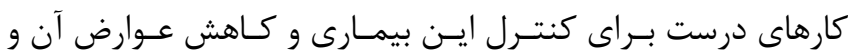
همجنين انجام رفتارهاى سالم دارد [1 ] امــا كيفيـت ايـن اطلاعـات

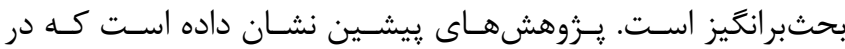
همه گيرىها، اطلاعات نادرست سلامت به رفتارهاى ير هرج و مــرج،

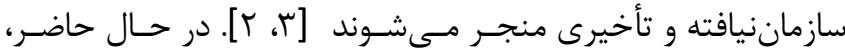

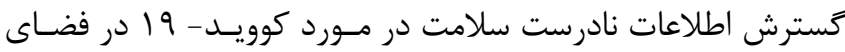
مجازى بارى بر دوش نظامهاى سلامت دنيا كذاشته است و آنها در

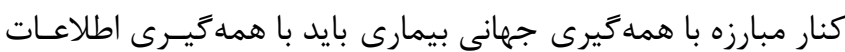

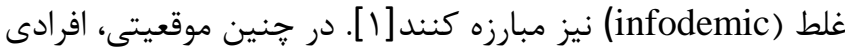

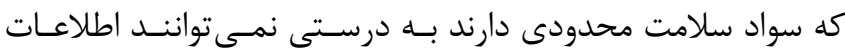

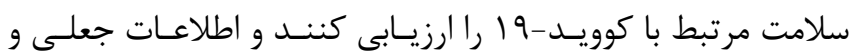
نادرست را از اطلاعات موثق و درست تشخيص دهند. افزون بـر آن، آنا يروهش هاى بيشين نشان داده است كه ميزان رفتارهاى ييشـيرانه

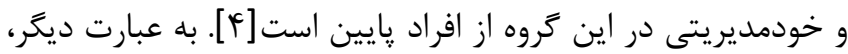

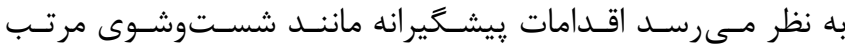

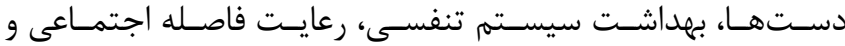
ضدعفونى كردن سطوح كه از الزامات مهار بيمارى كوويد-19 استـا در اين كروه از افراد به ميزان كمترى انجام مى شىود [هـ].

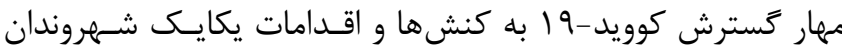

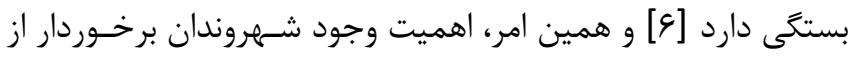

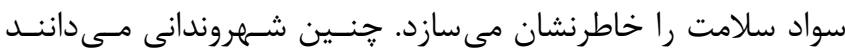

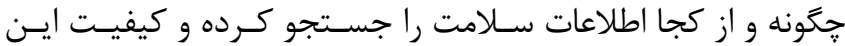

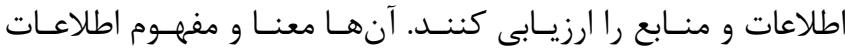

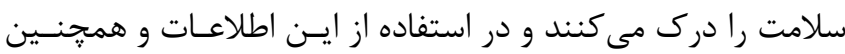

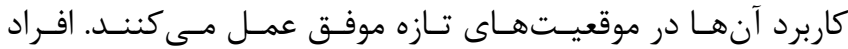

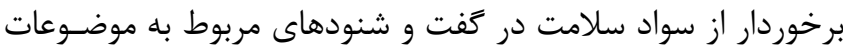

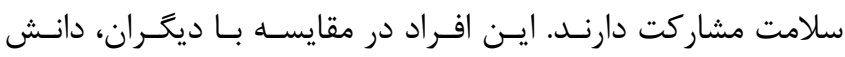
بيشترى نسبت به عوامل خطر بيمارى ها دارند و به درمانهـايى كـهـ

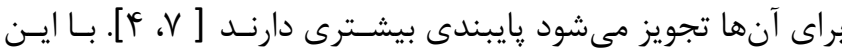


بر جهار زيربخش است (در جدول شماره ا ابـزار بــه جزئيـات آورده

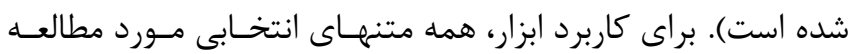

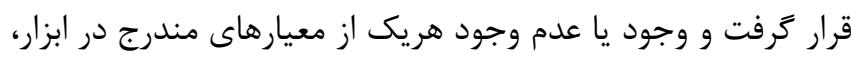

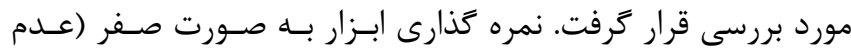
وجود معيار مورد نظر در متن) و ا (وجود معيار مورد نظر در مستن)

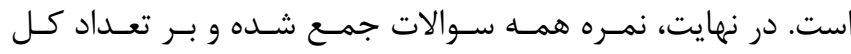

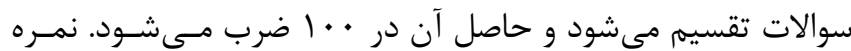
هريك از بخشها نيز، با همين روش محاسبه مىشود.

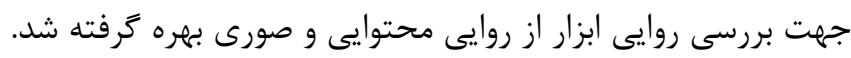

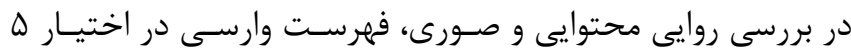

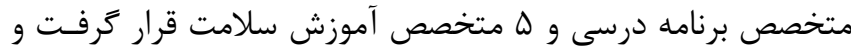

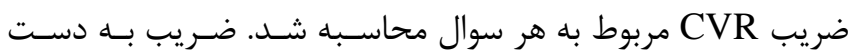

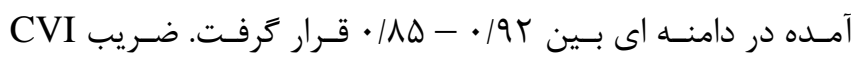
محاسبه شده براى كل سوالات فهرست برابر 191 • است.

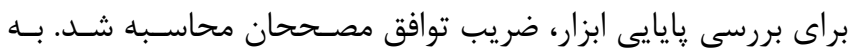

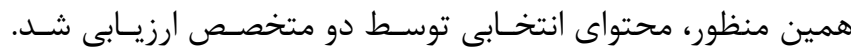

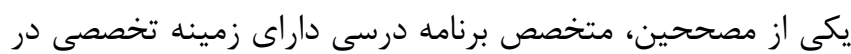

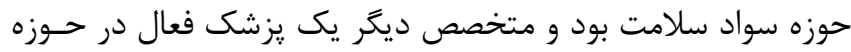

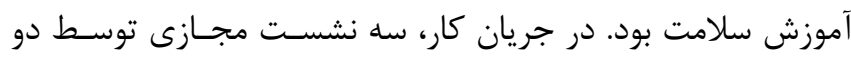

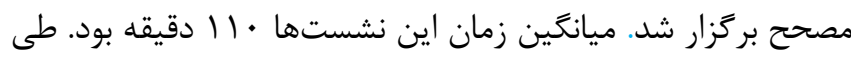

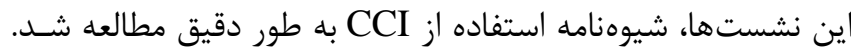

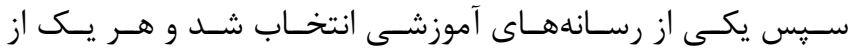

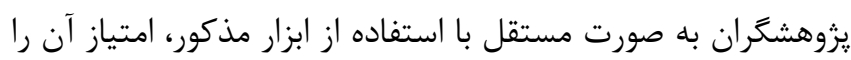

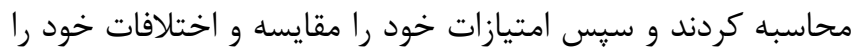

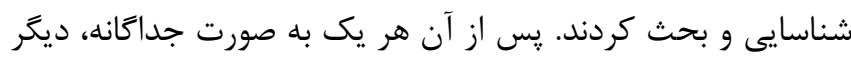

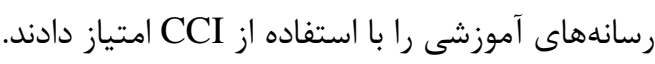

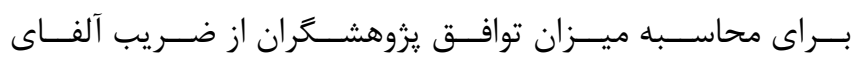

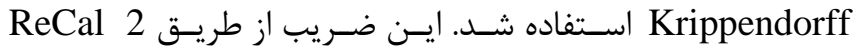
محاسبه شد. ReCal 2 يك برنامه برخط رايكان است كه با استفاده

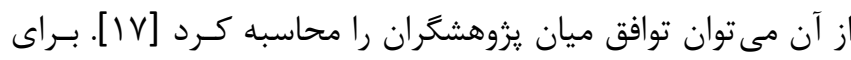

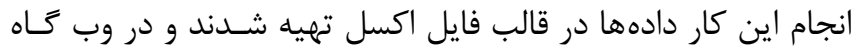

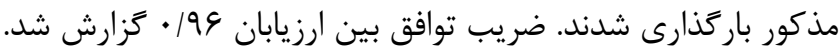

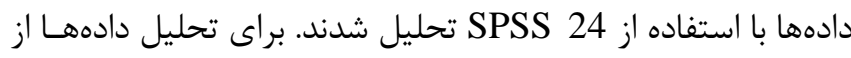

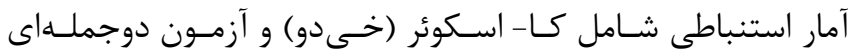

اسناد و منابع نوشتارى باركذارى شده مـرتبط بـا كرونـا در وبكَّـاه

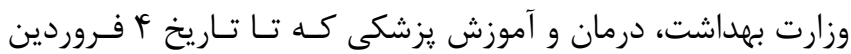

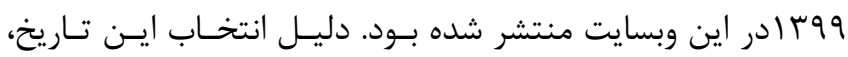

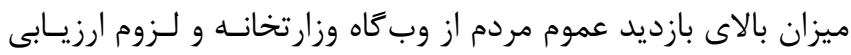
محتواى منتشرشده در زمان مطلوب و اجراى اصلاحات لازم در اين إنائ

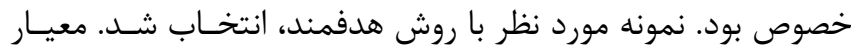

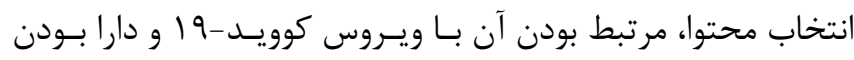

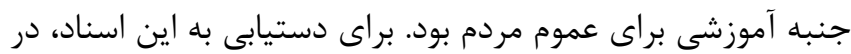
وب سايت مذكور در بخش جستجو وازه كرونا وارد شــد و در نهايست

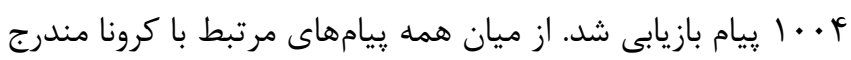

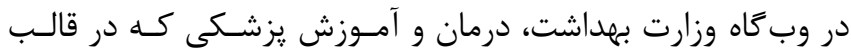

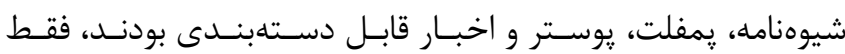

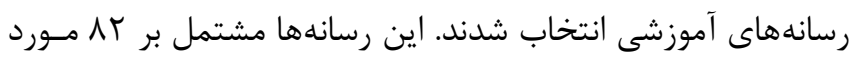
بودند. با توجه به هدف يزوهش، از ميان اين رسانهها فقط •و رسانه

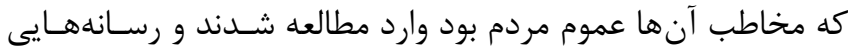

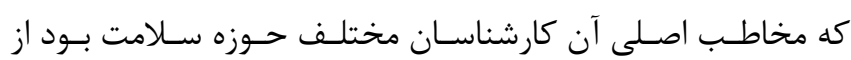

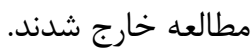

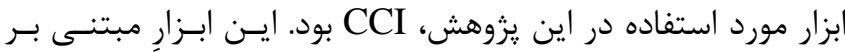

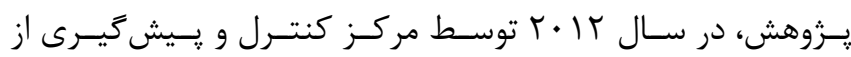

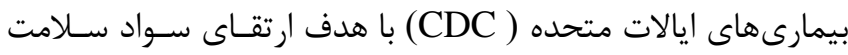
براى افراد داراى سواد سلامت محدود و ارزشيابى محصولات مرتبط

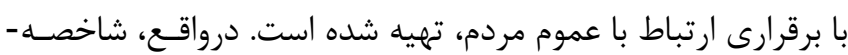
هاى مندرج در اين ابزار باتوجه به نيازهاى مخاطبان با سواد سلامت

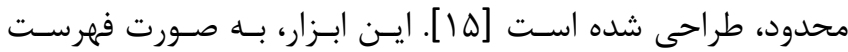

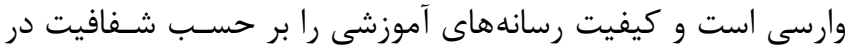

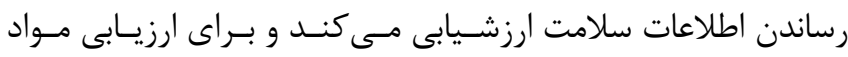

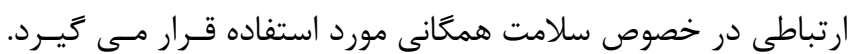

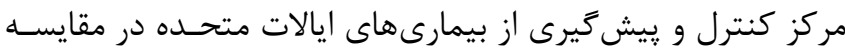

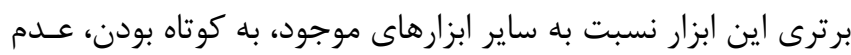

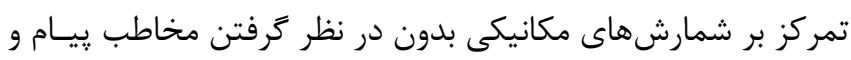

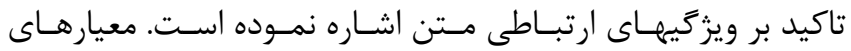

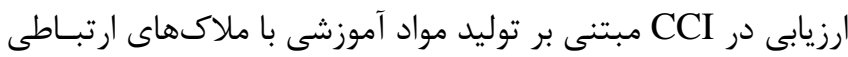

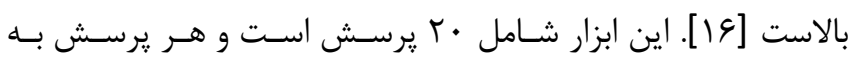
معيارى جهت ارزيابى محتوا اشاره دارد.

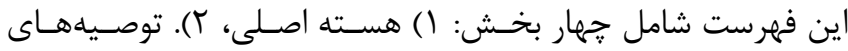

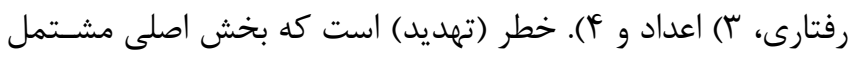


فاستفاده از افعال معلـوم (در مقابـل مجهـول) بـراى طراحسى بيـام و

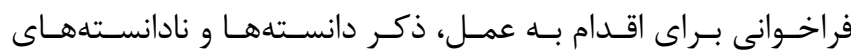

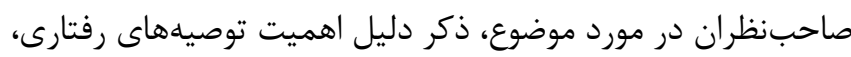

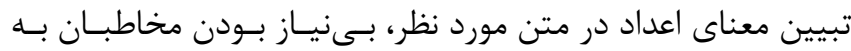

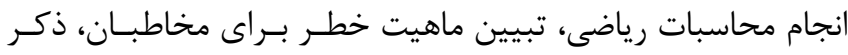

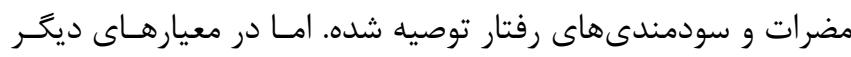

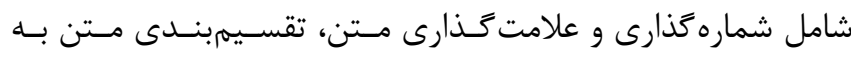

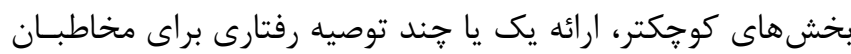

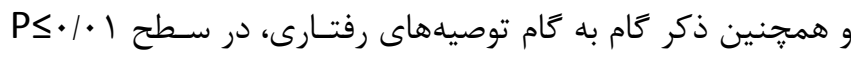
باته طور معنادار بالاتر از حد انتظار بودند.

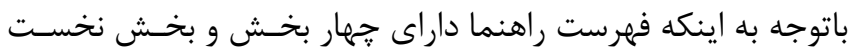

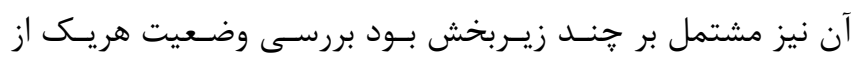

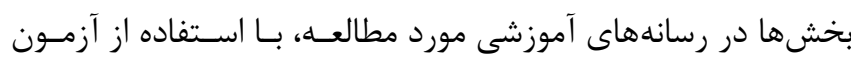

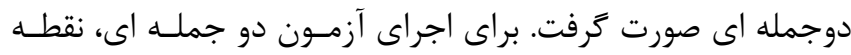

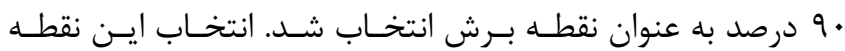
براساس نمره كذارى نسخه اصلى ابزار است.

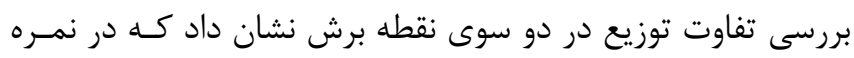

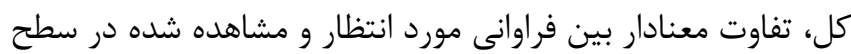

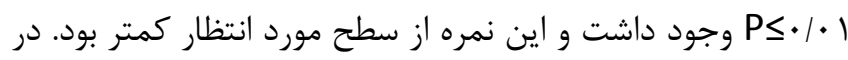

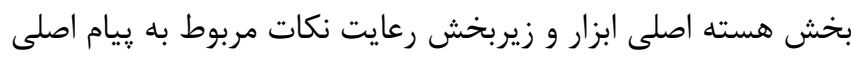

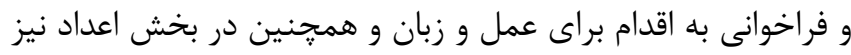

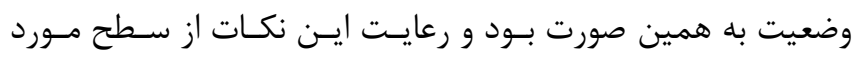

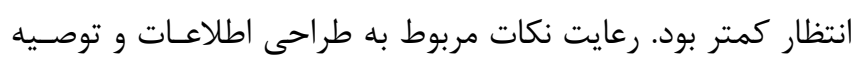
هاى رفتارى به صورت معنادارى از سـطح مـورد انتظــار بـالاتر بـود.

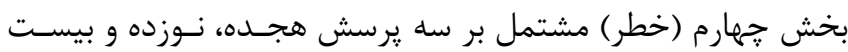
بود كه يرسش بيست در اين يروهش كاربردى نداشت و يافتـهـهـاى

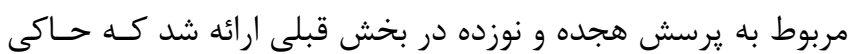
از كمتر بودن از سطح مورد انتظار بود.

\section{يافتهها}

در كل •4 رسانه آموزشى وارد مطالعه و نمرهدهى شد. فراوانى ايـن

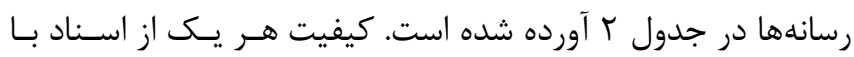

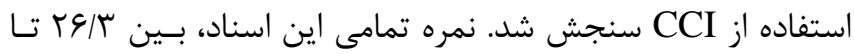

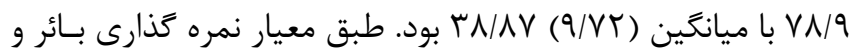

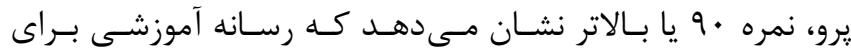

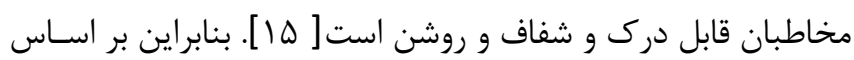
CCI به طور كلى رسانههاى آموزشى مرتبط با كرونا كه در وبكَّاه

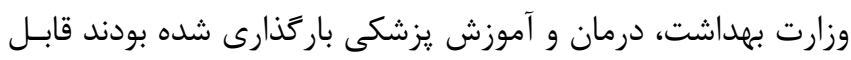
درك و شفاف نبودند. در هريك از رسانههاى آموزشى مرتبط با موضوع كوويد 9 آنه در در

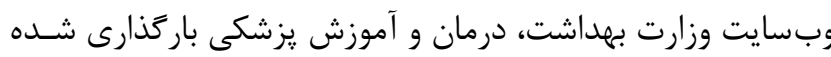

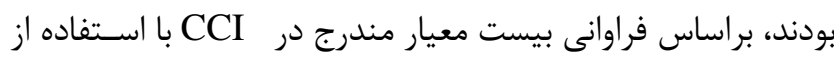

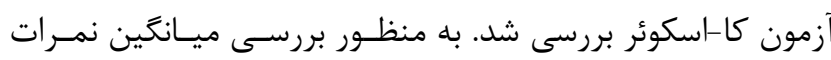

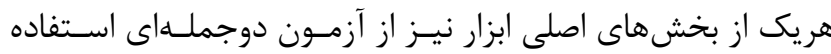

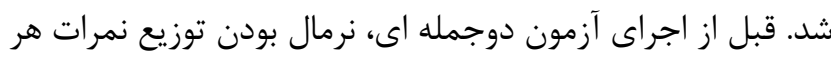

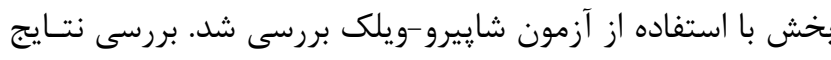

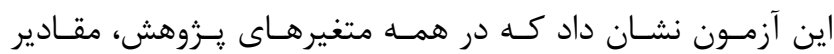

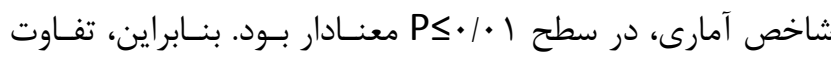

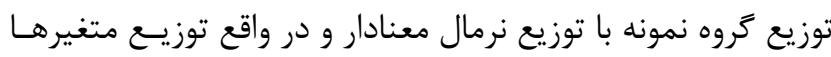

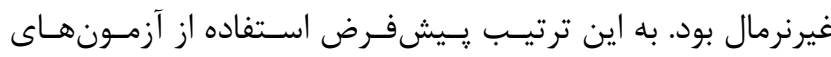

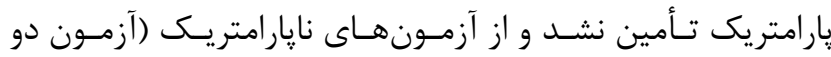
جملهاي) استفاده شد.

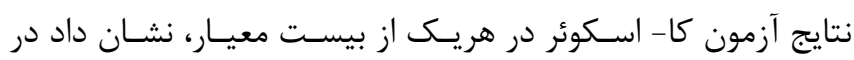

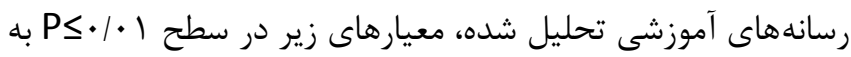

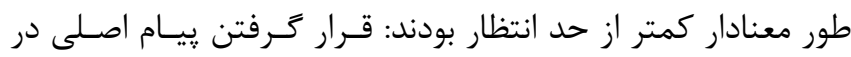

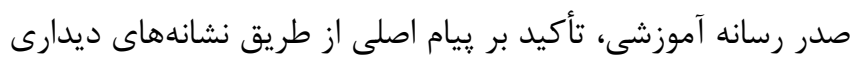

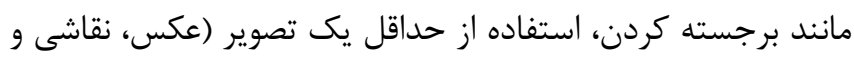

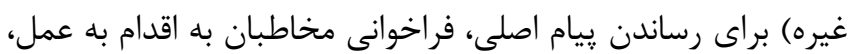


نشريه يروهشكده علوم بهداشتى جهاددانشكاهى

جدول ا: شاخص شفافيت ارتباطات (Clear Communication Index)

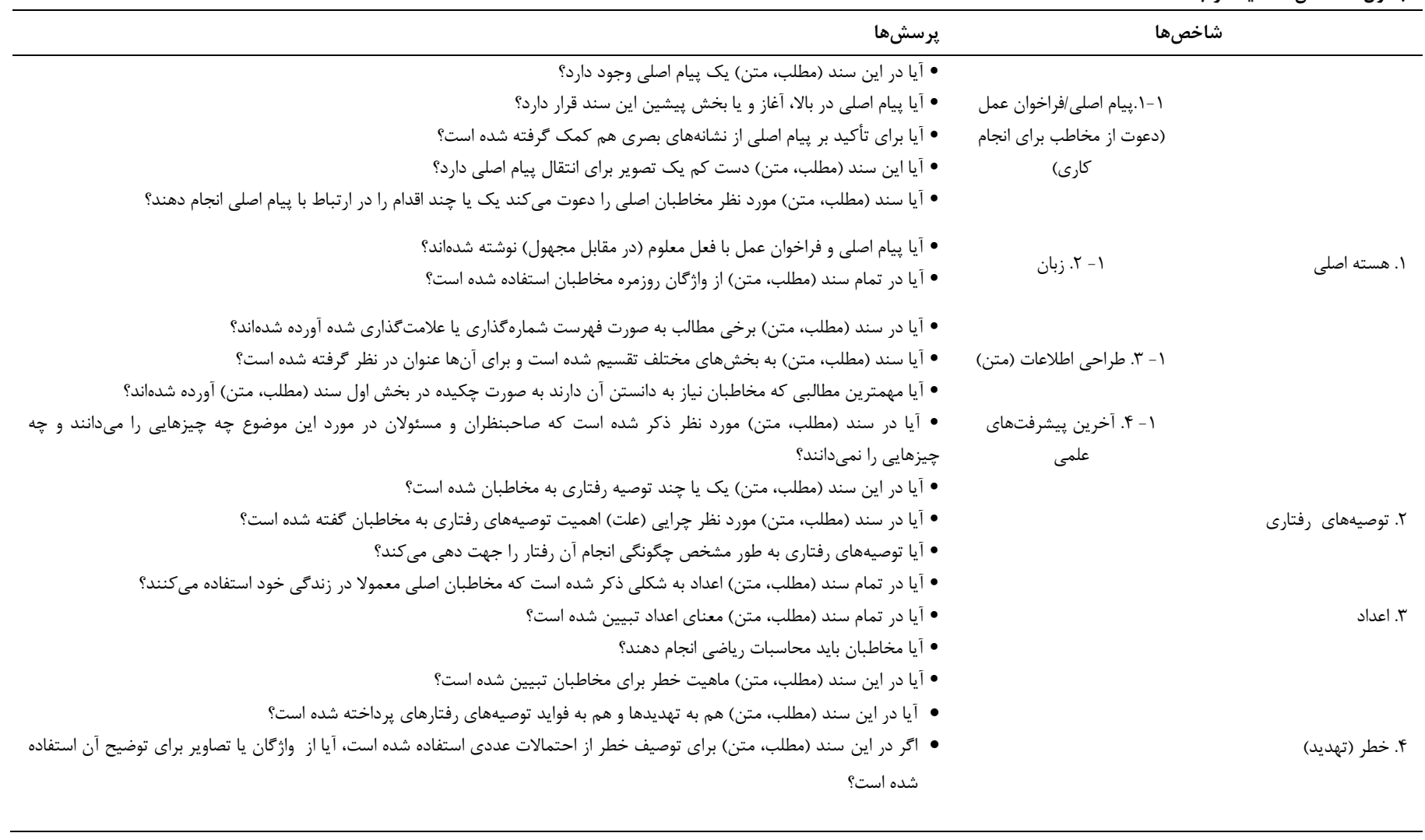

جدول r: فراوانى رسانههاى آموزشى بر حسب انواع

\begin{tabular}{|c|c|c|}
\hline درصد & تعداد & نوع رسانه آموزشى \\
\hline$\Delta G / V$ & rF & شيونامه \\
\hline rब/V & rr & يمفلت \\
\hline 919 & r & 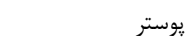 \\
\hline $1 .$. & 4. & جمع كل \\
\hline
\end{tabular}

جدول r: آزمون دو جملهاى

\begin{tabular}{|c|c|c|c|c|c|}
\hline \multirow[b]{2}{*}{ Paدار P P } & \multirow[b]{2}{*}{ نسبت مورد انتظار } & \multirow[b]{2}{*}{ نسبت مشاهده } & & \\
\hline & & & & تعداد & مولفه ها \\
\hline \multirow{3}{*}{$\cdot|\cdots|$} & $\cdot 11$ & $\cdot / 1 \Delta \Delta$ & Q1 & كمتر از نقطه برش (•9 -) & \\
\hline & & & & & ي بيام اصلى \\
\hline & .19 & $\cdot / 1 \Delta$ & 9 & بيشتر از نقطه برش ( •9+) & \\
\hline \multirow{3}{*}{$\cdot|\cdots|$} & $\cdot / 1$ & $\cdot / \Delta \Lambda$ & ra & كمتر از نقطه برش (•9-) & \\
\hline & & & & & زبان \\
\hline &.$/ 9$ & . At & ra & بيشتر از نقطه برش ( 9+) & \\
\hline \multirow{3}{*}{$\cdot \cdots \cdot 1$} & $\cdot / 1$ & $\cdot / / V$ & 1. & كمتر از نقطه برش (•9-) & \\
\hline & & & & & طراحى اطلاعات \\
\hline & $\cdot / 9$ & $\cdot / \Lambda r$ & $\Delta \cdot$ & بيشتر از نقطه برش ( 9+) & \\
\hline$\cdot \mid \cdots \cdot$ & $\cdot 11$ & $\cdot / 9$. & $\Delta r$ & كمتر از نقطه برش (•9-) & هسته اصلى \\
\hline
\end{tabular}


سال بيستم، شماره دوم، فروردين -ارديبهشت ..

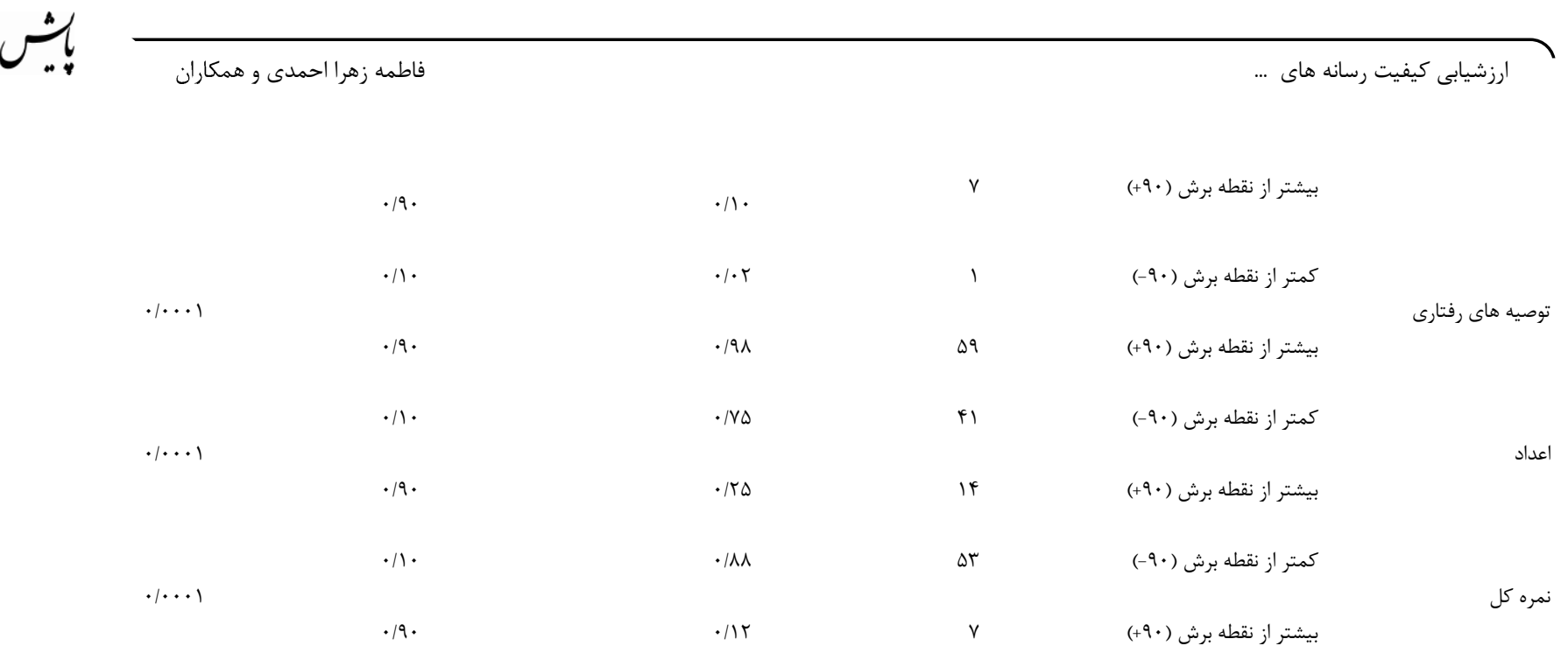

روزافزون به ويزه در موقعيتهـاى بحرانسى، يافتـهـهـاى علمسى تـازه

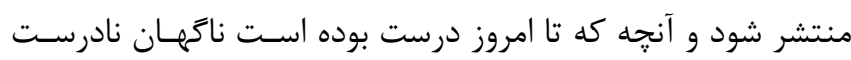

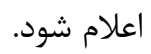
همسو با ثروهش Alpert و همكاران [ [r] در بيشـتر رسـانههـاى

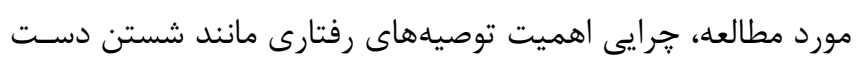

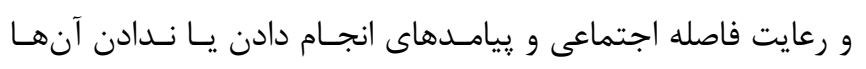

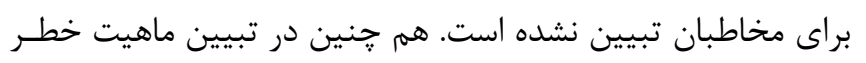

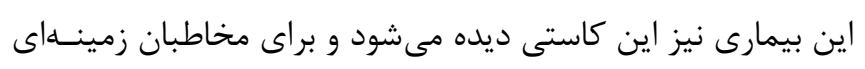

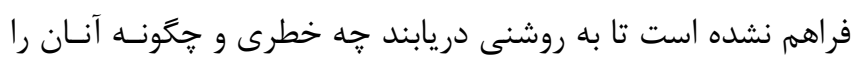

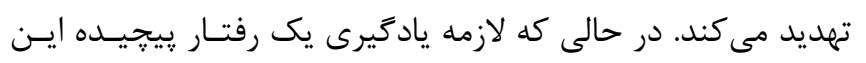

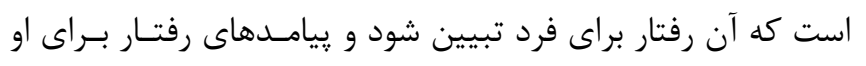

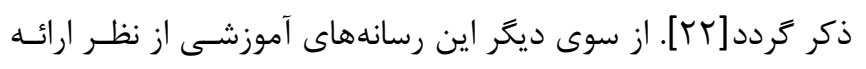

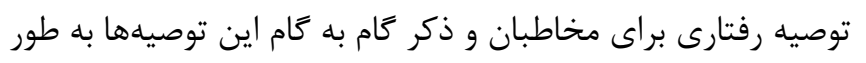

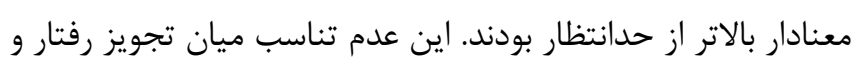

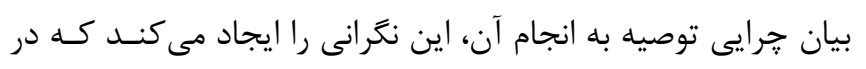

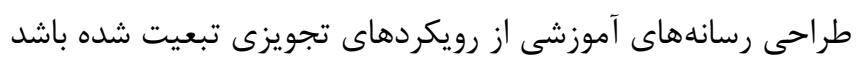

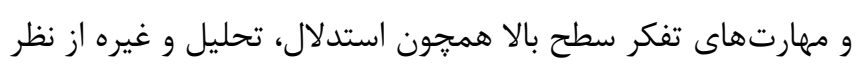

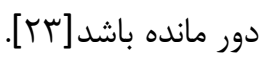

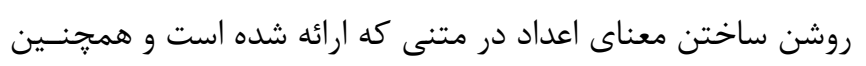

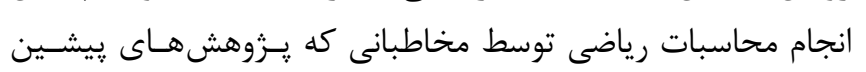
حكايت از محدود بودن سطح سواد سلامت آنان دارد كاسـتى دئى ديخـر

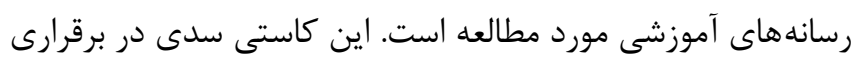

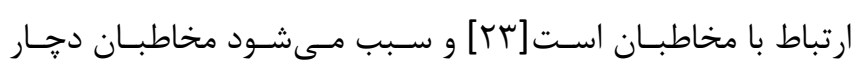

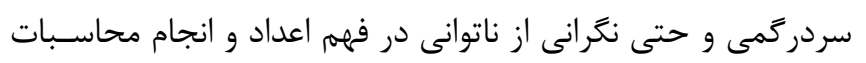

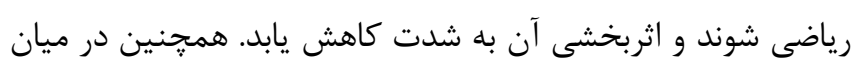

\section{بحث و نتيجه گيرى}

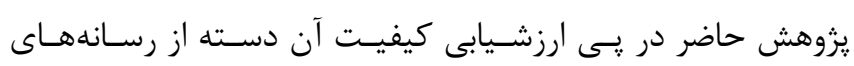

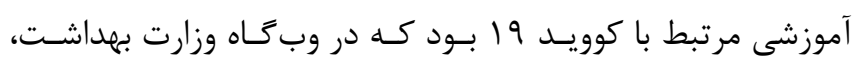

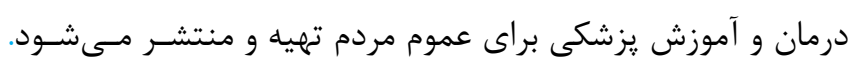

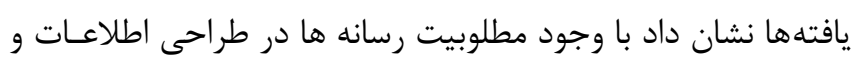

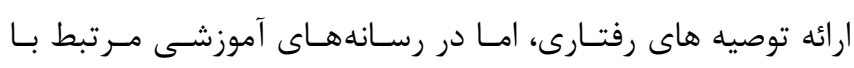

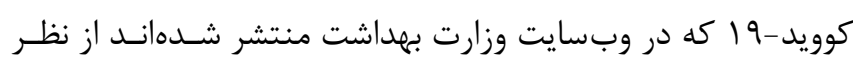

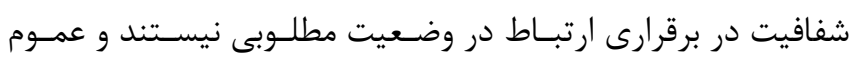

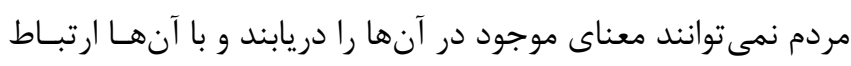

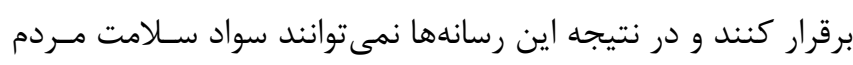

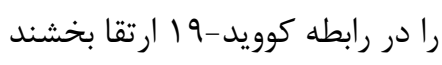

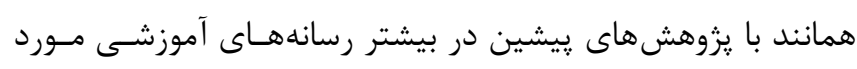

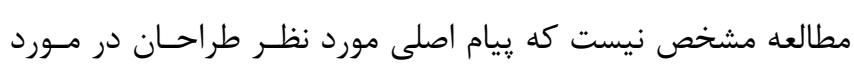

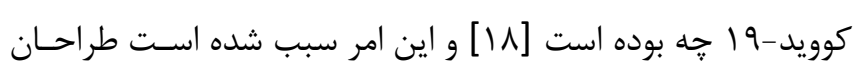

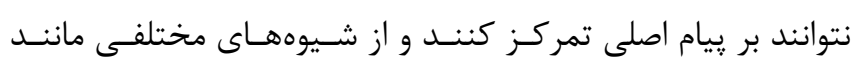

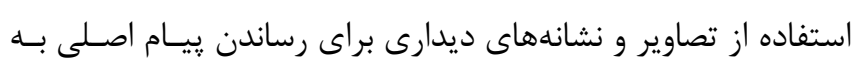

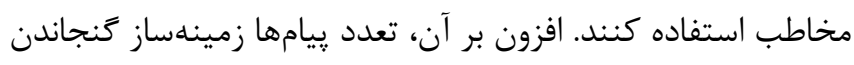

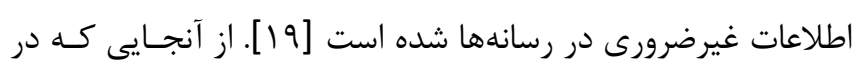

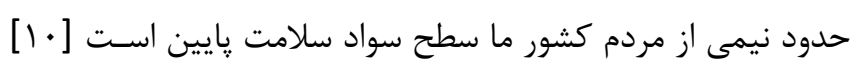

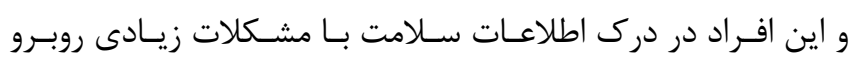

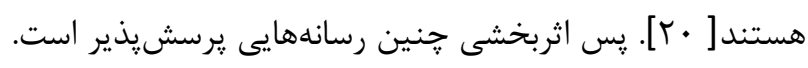

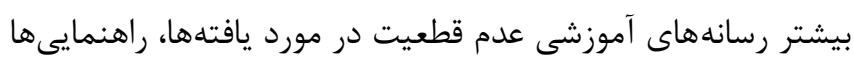

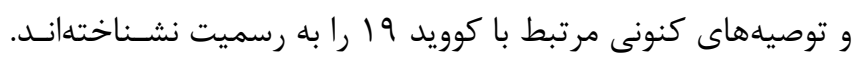

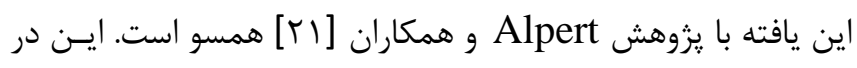

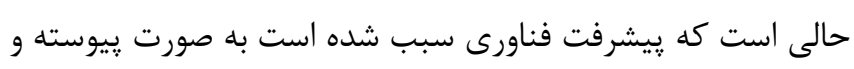


است، در حالى كه علاوه بر ايسن وبكَاه، سـاير وبكَاههـا و مطالـب منتشر شده در شبكه هاى اجتماعى نيز، مــورد توجــه عمـوم مـردم

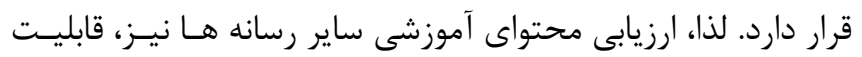
بررسى دارد. ضمن اينكه، مى توان رسانه ها را براساس ساير معيارها مورد ارزيابى دقيق تر قرار داد.

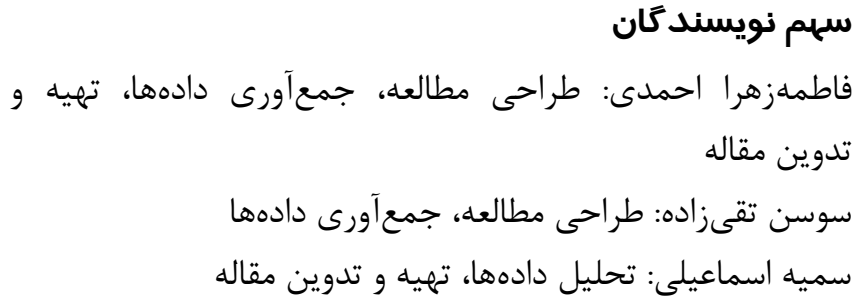
منابع

1. Zarocostas, John. How to fight an infodemic The Lancet 2020; 395: 676

2. Krishna, Arunima; Thompson, Teresa L. Misinformation about health: a review of health communication and misinformation scholarship. American Behavioral Scientist 2019; 00: 1-17

3. Song S, Zhao Y. C, Song X, \& Zhu Q. The Role of Health Literacy on Credibility Judgment of Online Health Misinformation. Paper presented at: IEEE International Conference on Healthcare Informatics (ICHI); 2019; 3: 10-13; Xi'an, China

4. Zarcadoolas C, Pleasant A, \& Greer D. S. Advancing health literacy: A framework for understanding and action $.1^{\text {st }}$ Edition. Jossey-Bass: San Francisco, 2009

5. World Health Organisaiton. Modes of transmission of virus causing COVID-19: implications for IPC precaution recommendations. Available at https://www.who.int/news-

room/commentaries/detail/modes-of-transmission-of-viruscausing-covid-19-implications-for-ipc-precautionrecommendations. Accessed APRIL 10, 2020.

6. Anderson RM, Heesterbeek H, Klinkenberg D, Hollingsworth TD. How will country-based mitigation measures influence the course of the COVID-19 epidemic? The Lancet 2020; 395: 931-934

7. Pleasant A. Health literacy: An opportunity to improve individual, community, and global health. New Directions for Adult and Continuing Education 2011; 130: 43-53

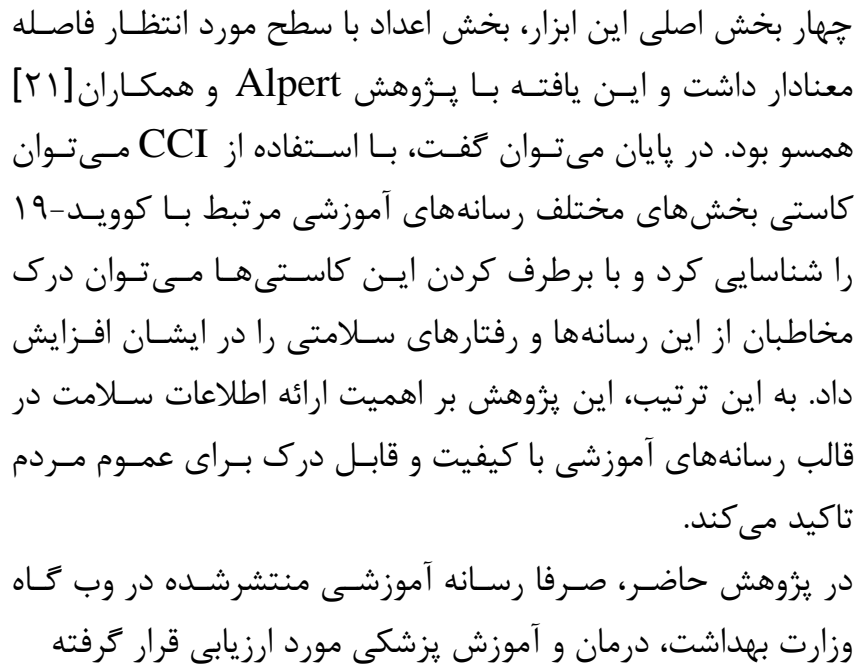

8. Von Wagner C, Knight K, Steptoe A, \& Wardle J. Functional health literacy and healthpromoting behavior in a national sample of British adults. Journal of Epidemiology \& Community Health 2007; 61: 1086-1090

9. Sørensen K, Van den Broucke S, Fullam J, Doyle G, Pelikan J, Slonska Z, \& Brand, H. Health literacy and public health: a systematic review and integration of definitions and models. BMC Public Health 2012; 12: 1-13

10. Tavousi M, Mehrizi A, Rafiefar Sh, Solimanian A ,Sarbandi F, Ardestani M, Hashemi A, Montazeri A. Health literacy in Iran: findings from a national study. Payesh 2015;15: 95-102 [In Persian]

11. Nguyen HC, Nguyen $\mathrm{MH}$, Do BN, Tran CQ, Nguyen TTP, Pham KM, et al. People with Suspected COVID-19 Symptoms Were More Likely Depressed and Had Lower Health-Related Quality of Life: The Potential Benefit of Health Literacy. Journal of Clinical Medicine 2020; 9: 1-18

12. Cataldi JR, Dempsey AF, O'Leary ST. Measles, the media, and MMR: Impact of the 2014-15 measles outbreak. Vaccine 2016; 34: 6375-6380

13. Dubé E, Gagnon D, Ouakki M, Bettinger J. A, Witteman H. O, MacDonald S, et al. Measuring vaccine acceptance among Canadian parents: A survey of the Canadian Immunization Research Network. Vaccine 2018; 36: 545-552

14. Baur $\mathrm{C}, \&$ Prue $\mathrm{C}$. The $\mathrm{CDC}$ clear communication index is a new evidence-based tool to 
prepare and review health information. Health Promotion and Practice 2014; 15: 629-637

15. Parmer J, Baur C. How CDC is promoting a clear communication culture. The European Medical Writers Association 2015; 24: 9-13

16. Freelon, D. G. ReCal: inter-coder reliability calculation as a web service. International Journal of Internet Science 2010; 5: 20-33

17. Saeed F, Anderson I. Evaluating the Quality and Readability of Internet Information on Meningiomas. World Neurosurgery 2017; 97: 312-316 18. Porter K J, Alexander R, Perzynski K. M, Kruzliakova N, \& Zoellner J. M. Using the Clear Communication Index to improve materials for a behavioral intervention. Health Communication 2019; 34: 782-788

19. Kaphingst K. A, DeJong W, Rudd R. E, \& Daltroy L. H. A content analysis of direct-toconsumer television prescription drug advertisements. Journal of Health Communication 2004; 9: 515-528
20. Alpert J. M Desens L, Krist A H, Aycock, R. A, \& KrepsG. L. Measuring health literacy levels of a patient portal using the CDC's Clear Communication Index. Health Promotion Practice 2017; 18: 140-149

21. Young, M. An Ecological Psychology of Instructional Design: Learning and Thinking by Perceiving-Acting Systems. In D. H. Jonassen (Ed.), Handbook of research on educational communications and technology Lawrence Erlbaum Associates Publishers: New Jersey, 2004

22. Zohar A. Higher order thinking in science classrooms: Students' learning and teachers' professional development. $1^{\text {st }}$ Edition, Springer :Dordrecht, 2004

23. Kelly K. M, Graves K. D, Harper F. W Schmidt J. E, Dickinson S. L, \& Andrykowski, M. A. Assessing perceptions of cancer risk: Does mode of assessment or numeracy matter? Cancer Detection and Prevention 2007; 31: 465-473 